\title{
Investigation of endothelial dysfunction and arterial stiffness in multisystem inflammatory syndrome in children
}

\author{
Murat Çiftel $^{1} \cdot$ Nurgül Ateş ${ }^{2} \cdot$ Osman Yılmaz $^{3}$ \\ Received: 7 April 2021 / Revised: 25 May 2021 / Accepted: 27 May 2021 / Published online: 2 July 2021 \\ (C) The Author(s), under exclusive licence to Springer-Verlag GmbH Germany, part of Springer Nature 2021
}

\begin{abstract}
Severe acute respiratory syndrome coronavirus 2 infection can result in multisystem inflammatory syndrome in children (MISC). MIS-C can lead to myocardial dysfunction, heart failure, and multiorgan failure; the primary finding is hyperinflammation. Endothelial dysfunction has not been evaluated in patients with MIS-C. We investigated endothelial dysfunction and arterial stiffness parameters in patients with MIS-C. The study included 38 pediatric patients ( 20 males and 18 females aged $4-17$ years, mean age 8.89 years) with MIS-C. Thirty-eight age- and sex-matched healthy individuals were enrolled as the control group. Systolic and diastolic ventricular measurements and systolic and diastolic measurements of ascending aorta diameter were performed by M-mode echocardiography. Endothelial dysfunction was evaluated using flow-mediated dilation by measuring the brachial artery diameter with a high-resolution probe. The MIS-C group had lower flow-mediated dilation than did the controls. The MIS-C group had decreased aortic strain and aortic distensibility values and correlations between decreased flowmediated dilation and reduced aortic strain, aortic distensibility, and reduced ejection fraction.

Conclusion: The results show that patients with MIS-C had endothelial dysfunction and arterial stiffness. Furthermore, the degree of endothelial dysfunction correlated with reduced ejection fractions.
\end{abstract}

\section{What is Known:}

-Endothelial dysfunction and arterial stiffness are unknown in patients with MIS-C.

- The effect of endothelial dysfunction and arterial stiffness on decreased cardiac function is unknown.

What is New:

-MIS-C patients have endothelial dysfunction and arterial stiffness.

- There is a link between left ventricular dysfunction and reduced endothelial dysfunction in patients with MIS-C.

Keywords Multisystem inflammatory syndrome in children · Flow-mediated dilation · Endothelial dysfunction · Arterial stiffness

\section{Communicated by Peter de Winter}

Murat Çiftel

nefrotik@hotmail.com

Nurgül Ateș

nurguldag@hotmail.com

Osman Y1lmaz

onfyilmaz@yahoo.com

1 Department of Pediatric Cardiology, Sanllurfa Training and Research Hospital, Mah. Yenice Yolu No: 1, Yenice, Eyyübiye/Sanliurfa, Turkey

2 Harran University, Şanlıurfa-Mardin Road Over 18.Km, Sanliurfa, Turkey

3 Department of Pediatric Cardiology, Etlik Training and Research Hospital, Ankara, Etlik, Turkey

\section{Introduction}

Coronavirus disease 2019 (COVID-19) is a viral respiratory disease characterized by hyperinflammation and cytokine storm caused by severe acute respiratory syndrome coronavirus 2 (SARS-CoV-2), which emerged in late 2019. SARS-CoV-2 is a single-stranded, positive-sense, enveloped RNA virus. It is thought to have originated in Wuhan City, Hubei Province, China [1]. After emerging in China, it spread rapidly worldwide, and the World Health Organization (WHO) declared COVID-19 a pandemic in March 2020 [2]. The first pediatric case of SARSCoV-2 infection was reported in China [3]. Cardiovascular involvement is a common and important complication of COVID19. Left heart failure and mitral insufficiency may occur as results of the direct cytotoxic effect of the virus and the resulting 
cytokine storm [3, 4]. Endothelial damage, endothelial dysfunction, hyperinflammation, direct myocardial injury, increased oxygen demand, side effects of various treatments, and electrolyte imbalance play roles in cardiovascular dysfunction [4-6]. With the spread of COVID-19 among children, multisystem inflammatory syndrome in children (MIS-C) was identified as a postinfectious hyperinflammatory disease with symptoms similar to Kawasaki disease occurring 6-8 weeks after SARS-CoV-2 infection $[7,8]$. MIS-C can lead to multiple organ failure, sometimes with cardiac involvement. Myocardial dysfunction, heart failure, and valvulitis are common presenting symptoms [8-10]. Endothelial dysfunction has been identified in the presence of inflammation $[11,12]$. The endothelium plays roles in the regulation of endothelial vascular tone, vascular remodeling, immunity, inflammation, and platelet aggregation. Endothelial dysfunction may result from mechanical damage, bacterial infection, hyperinflammation, and autoantibodies [13]. Flow-mediated dilation (FMD) of the brachial artery enables noninvasive assessment of systemic endothelial function and the endotheliumdependent vasodilatory response of a vessel to elevations in blood flow-associated shear stress [14]. Endothelial dysfunction is associated with arterial stiffness and atherosclerosis. COVID19 causes arterial stiffness and early vascular aging $[15,16]$. To our knowledge, endothelial dysfunction and arterial stiffness in MIS-C have not been studied. We investigated endothelial dysfunction and arterial stiffness and their correlations with the degree of cardiac involvement.

\section{Materials and methods}

\section{Study population}

This prospective study was approved by the hospital's ethics committee. Informed consent was obtained from all participants. Patients diagnosed with MIS-C in the Sanliurfa Training and Research Hospital between September 2020 and March 2021 were included in the study. Clinical diagnoses of MIS-C were made according to the diagnostic criteria of the US Centers for Disease Control and Prevention (CDC) and the WHO. MIS-C was diagnosed based on the presence of fever, signs of hyperinflammation, and multiorgan involvement, as well as evidence of association with COVID-19 and clinically severe disease requiring hospitalization in patients aged $<21$ years [8,9]. Diagnosis, treatment, and followup of patients with MIS-C were carried out by a multidisciplinary team that comprised staff from the Pediatric Cardiology, Pediatric Rheumatology, and Pediatric Infectious Diseases departments. The MIS-C group included persons aged 4-17 years. The control group comprised patients in whom heart disease was excluded by physical examination, electrocardiography, and echocardiography. The exclusion criteria were obesity, smoking, hypertension, congenital or acquired heart disease, and chronic kidney failure. In addition, children aged $<4$ years were excluded because of issues with image quality. No sedation was used for echocardiographic measurement. Individuals with technically insufficient echocardiographic images were excluded from the study.

Patients who were stable after the diagnosis of MIS-C underwent measurement in the pediatric cardiology clinic. Echocardiographic measurement of unstable patients was performed at the bedside in the intensive care unit. In the patient group, echocardiographic measurement was carried out before the initiation of treatments that could affect endothelial function (inotropic therapy, administration of intravenous immunoglobulin, systemic glucocorticoids, and anakinra). After routine echocardiographic imaging, systolic and diastolic Mmode measurement of the ascending aorta was performed to assess arterial stiffness. Brachial artery measurement was performed next to identify endothelial dysfunction using the FMD technique. For patients in the control group, measurement was performed in the pediatric cardiology clinic. The subjects' height, weight, systolic blood pressure (SBP), and diastolic blood pressure (DBP) were measured. SBP and DBP were measured from the right brachial artery with the subject in the supine position using a mercury pressure gauge prior to examination after $\geq 5$-min rest. The body mass index was calculated by dividing the body weight (in kilograms) by the square of the height (in meters).

\section{Echocardiographic examination}

Two-dimensional, M-mode, pulsed, and color flow Doppler echocardiographic examinations (Vivid S60N, 3-MHz transducer; GE, Horten, Norway) were performed by a pediatric cardiologist. During echocardiography, one-lead electrocardiography was recorded continuously. The systolic function of the left ventricle was evaluated using M-mode echocardiography in the parasternal long-axis view. Mitral insufficiency was detected using color Doppler based on the measurement of jet length (grade 1, jet length $\leq 1.5 \mathrm{~cm}$; grade 2 , jet length 1.5-2.9 $\mathrm{cm}$; grade 3, jet length 3.0-4.4 cm; grade 4, jet length $>4.5$ $\mathrm{cm})$. Grade 1 was accepted as mild insufficiency, grade 2 as moderate, and grades 3 and 4 as severe insufficiency [17].

\section{Determination of arterial stiffness}

Following routine echocardiography, the patients were placed on their left sides on their backs, and ascending aorta recordings were obtained in M-mode under two-dimensional guidance (Vivid S60N, 3-MHz transducer; GE). M-mode ascending aortic recordings were obtained $3 \mathrm{~cm}$ above the aortic valve. Aortic diameters were calculated by measuring the distance between the inner edges of the anterior and posterior walls in systole and diastole. The systolic aortic diameter 
(AoS) was measured with the aortic valve in the open position. The diastolic aortic diameter (AoD) was measured from the area corresponding to the QRS peak on simultaneous electrocardiographic recordings (Fig. 1). The following formulae were used to assess arterial elasticity: pulse pressure $(\mathrm{PP})=$ $\mathrm{SBP}-\mathrm{DBP}$, aortic strain $(\%)=[(\mathrm{AoS}-\mathrm{AoD}) \div \mathrm{AoD}] \times 100$, and aortic distensibility $=2 \times[\mathrm{AoS}-\mathrm{AoD} \div \mathrm{AoD}] \times \mathrm{PP}[18]$.

\section{Flow-mediated dilation measurement}

The brachial artery diameter was measured in the antecubital fossa immediately before its branching using a Doppler ultrasound system with a high-resolution transducer (Vivid S60N, $12 \mathrm{MHz}$ linear-array transducer; GE). For two-dimensional imaging, a segment with clearly identifiable anterior and posterior intimal faces was selected. The brachial artery diameter was measured three times, and the average was recorded as the basal diameter. Measurements of the brachial artery were taken at the end of diastole according to electrocardiography monitoring. The cuff of the blood pressure device was placed in the upper part of the right antecubital fossa to create current impulses in the brachial artery. After baseline measurements were recorded, the cuff pressure was increased to $50 \mathrm{mmHg}$ above the SBP, and the cuff was held in this position for 5 min to allow complete interruption of arterial flow. Anterograde blood flow was cut, and ischemia was induced. Sixty seconds after the cuff was deflated, two-dimensional longitudinal images of the brachial artery were obtained. FMD values were calculated using the baseline and maximum diameters of the brachial artery. FMD was calculated as: FMD $=100 \times$ (maximum diameter after hyperemia - baseline diameter $\div$ baseline diameter) [18].

\section{Statistical analysis}

SPSS statistical software (version 15.0; SPSS Inc., Chicago, IL, USA) was used for all statistical analyses. Values are medians or means \pm standard deviations. Pearson's chi-squared test was used to examine differences in sex distribution and to assess the normality of the data distribution; the Shapiro-Wilk test was used for all other variables. The nonparametric Mann-Whitney $U$ test was performed for non-normally distributed variables. Spearman's correlation analysis was conducted to evaluate correlations. $P$ values $<0.05$ were considered to indicate statistical significance.

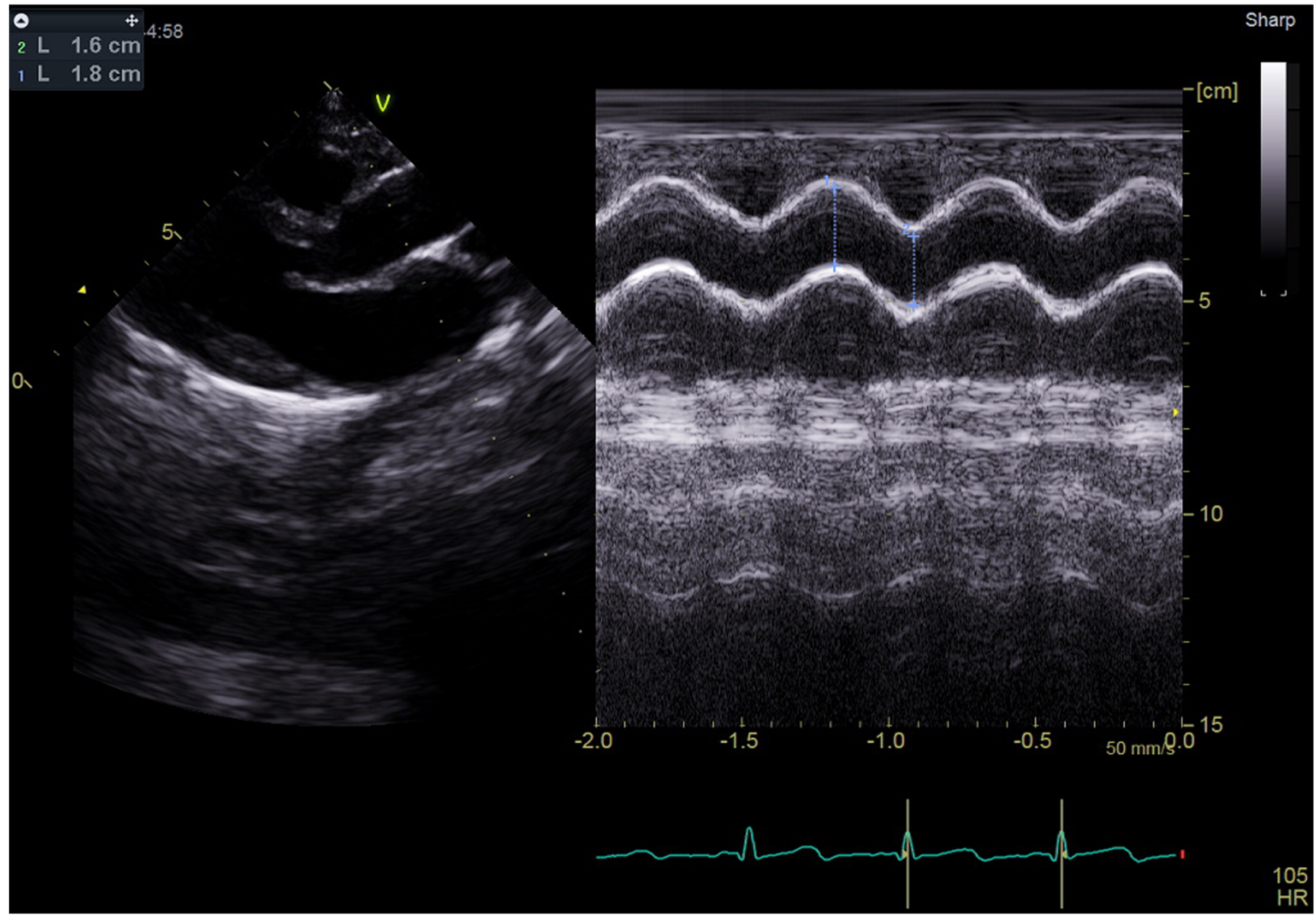

Fig. 1 Aortic systolic diameter and aortic diastolic diameter measurements 


\section{Results}

The study included 38 pediatric patients ( 20 males and 18 females, mean age 8.89 years) who were matched for age, body mass index, and sex with control subjects. The ejection fractions of $20(52 \%)$ patients were $<55 \%$. No patient had a coronary artery aneurysm. However, dilatation of the coronary arteries $(Z$ score $2-2.5)$ was detected in five $(13 \%)$ patients. Five patients had severe, 7 patients had moderate, and 10 patients had mild mitral valve insufficiency. Overall, 58\% of patients had mitral insufficiency. In addition, seven (18\%) patients showed minimal pericardial effusion. Some patients with MIS-C required intensive care (20/38, 53\%), intravenous immunoglobulin $(38 / 38,100 \%)$, anakinra $(25 / 38,66 \%)$, pulse steroid $(16 / 38,42 \%)$, and inotropic therapy $(26 / 38,68 \%)$. Some patients in the MIS-C group showed reverse transcription polymerase chain reaction test positivity $(3 / 38,8 \%)$, serological positivity for COVID-19 (37/38, 97\%), and histories of COVID-19 contact $(35 / 38,92 \%)$. The inflammatory marker values were as follows: white blood cell count, 2150 $47,500 / \mu \mathrm{L}$ (mean $14,004 / \mu \mathrm{L}$, reference range $6000-17,500 /$ $\mu \mathrm{L}$ ); C-reactive protein concentration, $18-327 \mathrm{mg} / \mathrm{L}$ (mean $152 \mathrm{mg} / \mathrm{L}$, reference range $0-5 \mathrm{mg} / \mathrm{L}$ ); procalcitonin concentration, $0.15-100 \mathrm{ng} / \mathrm{mL}$ (mean $12 \mathrm{ng} / \mathrm{mL}$, reference range 0 $0.04 \mathrm{ng} / \mathrm{mL}$ ); and ferritin concentration $75-2576 \mathrm{ng} / \mathrm{mL}$ (mean $579 \mathrm{ng} / \mathrm{mL}$, reference range $7-140 \mathrm{ng} / \mathrm{mL}$ ). In addition, $27(71 \%)$ patients in the MIS-C group had increased troponin $\mathrm{T}$ levels (100-980 ng/L, reference range 5-100 ng/L), indicative of cardiac involvement.

On M-mode echocardiography, no difference between groups was observed in the end-diastolic or end-systolic interventricular septal wall thickness or left ventricular posterior wall thickness (all $p>0.05$ ). However, the MIS-C group had significantly increased left ventricular end-diastolic and endsystolic diameters (both $p<0.05$ ) and decreased ejection fractions $(p<0.01)$ compared with the control group. The clinical characteristics and echocardiographic findings are provided in Table 1.

The MIS-C and control groups had similar pulse pressure $(38.13 \pm 8.62$ and $40.63 \pm 3.67$, respectively; $p=0.10)$, systolic aortic diameter $(2.11 \pm 0.21$ and $2.21 \pm 0.25$, respectively; $p=0.66)$, and diastolic aortic diameter $(1.91 \pm 0.20$ and $1.89 \pm 0.24$, respectively; $p=0.81$ ). Compared with the control group, patients with MIS-C had decreased aortic strain $(11.64 \pm 5.30$ vs. $17.07 \pm 4.44 ; p<0.01)$ and aortic distensibility $(8.90 \pm 4.30$ vs. $13.91 \pm 3.70 ; p<0.01)$. Patients in the MIS-C group also had decreased brachial artery diameter changes $(0.29 \pm 0.12$ vs. $0.40 \pm 0.13 ; p<0.01)$ and FMD $(9.20 \pm 3.81$ vs. $12.10 \pm 3.80 ; p<0.01)$ relative to the controls (Table 2). There was a weak correlation between FMD and aortic strain $(\mathrm{r}=0.39, \mathrm{p}<0.05)$ and aortic distensibility $(\mathrm{r}=$ $0.42, \mathrm{p}<0.05)$. There was a positive correlation $(\mathrm{r}=0.67, \mathrm{p}$ $<0.01$ ) between FMD and ejection fractions. In addition, there
Table 1 Clinical characteristics and results of conventional echocardiography

\begin{tabular}{llll}
\hline & MíS-C (38 patients) & Controls (38 subjects) & P value \\
\hline Age (years) & $8.89 \pm 2.67$ & $8.94 \pm 2.69$ & 0.82 \\
BMI (kg/m²) & $19.63 \pm 2.31$ & $20.13 \pm 1.84$ & 0.30 \\
SBP (mmHg) & $99.60 \pm 14.7$ & $108.92 \pm 6.27$ & .001 \\
DBP (mmHg) & $61.47 \pm 9.60$ & $68.15 \pm 5.87$ & .001 \\
IVSd (mm) & $6.21 \pm 1.09$ & $6.07 \pm 1.26$ & 0.62 \\
LVIDd (mm) & $43.07 \pm 5.32$ & $40.42 \pm 5.29$ & 0.03 \\
LVPWd (mm) & $5.76 \pm 1.26$ & $5.63 \pm 1.38$ & 0.66 \\
IVSs (mm) & $9.71 \pm 1.37$ & $9.68 \pm 2.02$ & 0.94 \\
LVIDs (mm) & $27.73 \pm 4.79$ & $25.28 \pm 3.74$ & 0.01 \\
LVPWs (mm) & $9.31 \pm 1.61$ & $9.26 \pm 1.55$ & 0.88 \\
EF & $54.78 \pm 15.10$ & $66.94 \pm 4.41$ & .001 \\
\hline
\end{tabular}

$B M I$ body mass index, $S B P$ systolic blood pressure, $D B P$ diastolic blood pressure, IVSd interventricular septal wall thickness diastolic, $L V I D d$ left ventricular internal dimension diastolic, $L V P W d$ left ventricular posterior wall thickness diastolic, IVSs interventricular septal wall thickness systolic, $L V I D s$ left ventricular internal dimension systolic, $L V P W s$ left ventricular posterior wall thickness systolic, $E F$ ejection fraction. Data are expressed as mean \pm standard deviation

was a significant positive correlation $(\mathrm{r}=0.81, \mathrm{p}<0.01)$ between FMD and reduced ejection fraction (below 55\%). In the MIS-C group, the correlation between flow-mediated dilatation and ejection fraction is given in Fig. 2.

\section{Discussion}

MIS-C affects the heart, lungs, kidneys, brain, skin, eyes, and gastrointestinal tract; however, its cause is unknown. SARS-

Table 2 Arterial stiffness values and flow-mediated dilation of the brachial artery

\begin{tabular}{llll}
\hline & MíS-C (38 patients) & Controls (38 subjects) & P value \\
\hline PP & $38.13 \pm 8.62$ & $40.63 \pm 3.67$ & 0.10 \\
AoS $(\mathrm{cm})$ & $2.11 \pm .21$ & $2.21 \pm 0.25$ & 0.66 \\
AoD $(\mathrm{cm})$ & $1.91 \pm 0.20$ & $1.89 \pm 0.24$ & 0.81 \\
AS $(\%)$ & $11.64 \pm 5.30$ & $17.07 \pm 4.44$ & $<0.01$ \\
AD & $8.90 \pm 4.30$ & $13.91 \pm 3.70$ & $<0.01$ \\
BABd $(\mathrm{mm})$ & $3.22 \pm 0.36$ & $3.29 \pm 0.36$ & 0.41 \\
BAMd $(\mathrm{mm})$ & $3.52 \pm 0.42$ & $3.70 \pm 0.41$ & 0.07 \\
BADc $(\mathrm{mm})$ & $0.29 \pm 0.12$ & $0.40 \pm 0.13$ & $<0.01$ \\
FMD $(\%)$ & $9.20 \pm 3.81$ & $12.10 \pm 3.80$ & $<0.01$ \\
\hline
\end{tabular}

$P P$ pulse pressure, $A o S$ aortic systolic diameter, $A o D$ aortic diastolic diameter, $A S$ aortic strain, $A D$ aortic distensibility, $B A B d$ brachial artery baseline diameter, $B A M d$ brachial artery maximum diameter after hyperemia, $B A D c$ brachial artery diameter change, $F M D$ flow-mediated dilation. Data are expressed as mean \pm standard deviation 


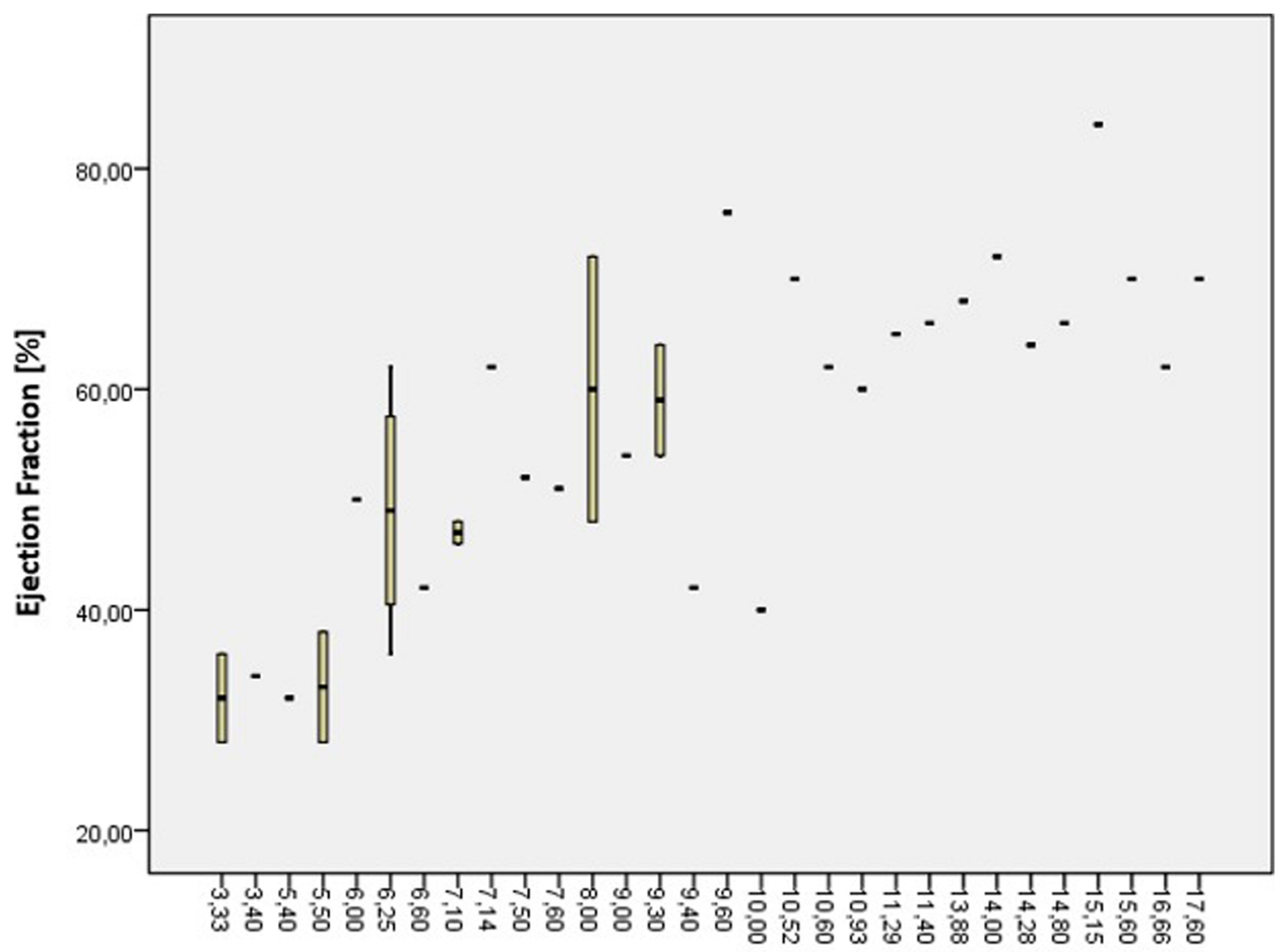

\section{Flow Mediated Dilation [\%]}

Fig. 2 Correlation between ejection fraction and flow-mediated dilatation in the MISC patient group

$\mathrm{CoV}-2$ infection is typically mild and often asymptomatic in children, but some children develop MIS-C after acquiring it. MIS-C is characterized by fever, hyperinflammation, and multiorgan involvement and typically occurs 6-8 weeks after COVID-19 onset. The symptoms of MIS-C are similar to those of toxic shock syndrome and Kawasaki disease [7, 8]. The majority of affected children show polymerase chain reaction negativity for SARS-CoV-2. Most patients have positive serology as a sign of previous COVID-19, suggesting that MIS-C is a result of the immune dysregulation that develops after COVID-19 [8, 19]. MIS-C was first reported in Italy as an increase in the incidence of Kawasaki-like disease [7]. Later, the CDC and WHO published a case definition for MIS-C associated with COVID19 [20, 21]. In MIS-C, systolic and diastolic heart functions are often impaired. Even after the recovery of systolic heart function, diastolic heart function deterioration has been detected [22]. Most patients have elevated troponin I or brain natriuretic peptide levels, which are signs of cardiac damage [9, 10]. Hyperinflammation, complement activation, microvascular damage, and endothelial damage have been detected in patients with MIS-C [23, 24]. The known causes of endothelial dysfunction are hyperinflammation, microvascular damage, and endothelial damage [13]. Left ventricular myocardial dysfunction is the most common cardiac finding of MIS-C. Heart failure is linked to endothelial dysfunction [25].

The endothelium is critical for the maintenance of vascular balance. Endothelial dysfunction can be defined as impaired endothelial vasodilation as a result of decreased nitric oxide release, increased nitric oxide degradation, or increased release of vasoconstriction mediators [13]. FMD is used to noninvasively assess nitric oxide-dependent vasoactivity $[13,14,23]$. Endothelial dysfunction can be caused by mechanical forces, bacterial infection, inflammation, and autoantibodies in circulation [26]. SARS-CoV-2 enters host cells via the angiotensinconverting enzyme-2 receptor, which is found in the respiratory tract and endothelial cells [1,27]. Endothelial dysfunction and arterial stiffness have been detected in patients with COVID-19. Endothelial dysfunction and impaired microcirculatory function significantly contribute to life-threatening complications of COVID-19, such as venous thromboembolic disease and multiple organ involvement $[16,28]$. We found that FMD values were decreased, indicating endothelial dysfunction, in patients with MIS-C. In MIS-C, endothelial dysfunction may cause cardiovascular and other organ involvement. Endothelial dysfunction has been detected in heart failure [25]. We found a positive correlation between decreased ejection fractions and 
decreased FMD. Thus, treatments for endothelial dysfunction (angiotensin-converting enzyme inhibitors, antioxidants, beta blockers, endothelial nitric oxide synthase enhancers, and phosphodiesterase-5 inhibitors) may be an option [29]. However, further studies are needed.

MIS-C is characterized by hyperinflammation, and inflammation plays an important role in arterial stiffness. Furthermore, endothelial dysfunction may lead to atherosclerosis and arterial stiffness. Increased arterial stiffness is associated with an increased risk of cardiovascular events, such as stroke [11, 12, 16]. Increased arterial stiffness also increases the load on the heart - more effort is required to maintain the heart rate. Over time, this increased workload can lead to left ventricular hypertrophy and remodeling, resulting in heart failure. Moreover, it increases the afterload on the heart, leading to an increase in cardiac workload and contributing to heart failure $[15,16]$. We found decreased aortic strain and distensibility, indicating increased arterial stiffness, in patients with MIS-C. Arterial stiffness is linked to inflammation and endothelial dysfunction. Whether increased arterial stiffness causes cardiovascular events in patients with MIS-C, however, remains unclear.

This study has several limitations. First, the patients were not followed prospectively for the recording of cardiovascular events. Thus, we could not determine whether endothelial dysfunction or arterial stiffness is a determinant of cardiovascular events. Second, endothelial dysfunction and arterial stiffness were not evaluated after recovery. Thus, we could not determine whether these changes are permanent or occur only in the acute phase of the disease. Third, the assessment of endothelial dysfunction by FMD is subject to intraobserver variability. Although FMD measurements were made within the first hour, intravenous fluids (colloids, crystalloids, and dextrose fluids) can alter endothelial function.

In conclusion, this study is the first in which endothelial dysfunction and arterial elasticity were investigated in patients with MIS-C. We found endothelial dysfunction and impaired arterial elasticity in these patients. Furthermore, the degree of endothelial dysfunction correlated with arterial stiffness and reduced ejection fractions. In patients with MIS-C, endothelial dysfunction may be a precursor of multiorgan failure, and therapeutic approaches for endothelial dysfunction may be beneficial. Comprehensive prospective studies of this topic are needed.

\footnotetext{
Abbreviations COVID-19, Coronavirus disease 2019; CDC, US Centers for Disease Control and Prevention; $D B P$, Diastolic blood pressure; $F M D$, Flow-mediated dilation; $M I S$, Multisystem inflammatory syndrome in children; $S A R S-C o V-2$, Severe acute respiratory syndrome coronavirus 2; SBP, Systolic blood pressure; WHO, World Health Organization
}

Authors' contributions Murat Ciftel: idea of the study, research, planning, data collection, writing, and statistical analysis. Nurgül Ateș: article writing and data collection. Osman Yilmaz: article writing and data collection.
Data Availability The datasets analyzed during the current study are available from the corresponding author on reasonable request.

Code availability Not applicable.

\section{Declarations}

Ethics approval This study was approved by the Ethics Committee, Harran University (approval number: 0206-2020).

Consent to participate Not applicable.

Consent for publication Not applicable.

Conflict of interest The authors declare no competing interests.

\section{References}

1. Guan WJ, Ni ZY, Hu Y, Liang WH, Ou CQ, He JX, Liu L, Shan H, Lei CL, Hui DSC, du B, Li LJ, Zeng G, Yuen KY, Chen RC, Tang CL, Wang T, Chen PY, Xiang J, Li SY, Wang JL, Liang ZJ, Peng YX, Wei L, Liu Y, Hu YH, Peng P, Wang JM, Liu JY, Chen Z, Li G, Zheng ZJ, Qiu SQ, Luo J, Ye CJ, Zhu SY, Zhong NS, China Medical Treatment Expert Group for Covid-19 (2020) China Medical Treatment Expert Group for Covid-19. Clinical Characteristics of Coronavirus Disease 2019 in China. N Engl J Med 382:1708-1720. https://doi.org/10.1056/NEJMoa2002032

2. World Health Organization (WHO). WHO Director-General's opening remarks at the media briefing on COVID-19: 11 March 2020. Published March 11, 2020. Accessed March 11, 2020. https://www.who.int/dg/speeches/detail/who-directorgeneral-s-opening-remarks-at-the-media-briefing-on-covid-19\% 2D\%2D-11-march-2020

3. Chan JF, Yuan S, Kok KH, To KK, Chu H, Yang J et al (2020) A familial cluster of pneumonia associated with the 2019 novel coronavirus indicating person-to-person transmission: a study of a family cluster. Lancet 395:514-523. https://doi.org/10.1016/S01406736(20)30154-9

4. Tezer H, Bedir DT (2020) Novel coronavirus disease (COVID-19) in children. Turk J Med Sci 50:592-603. https://doi.org/10.3906/ sag-2004-174

5. Bansal M (2020) Cardiovascular disease and COVID-19. Diabetes Metab Syndr 14:247-250. https://doi.org/10.1016/j.dsx.2020.03. 013

6. Xiong TY, Redwood S, Prendergast B, Chen M (2020) Coronaviruses and the cardiovascular system: acute and longterm implications. Eur Heart J 41:1798-1800. https://doi.org/10. 1093/eurheartj/ehaa231

7. Verdoni L, Mazza A, Gervasoni A, Martelli L, Ruggeri M, Ciuffreda M (2020) An outbreak of severe Kawasaki-like disease at the Italian epicentre of the SARS-CoV-2 epidemic: an observational cohort study. Lancet 395:1771-1778. https://doi.org/10. 1016/S0140-6736(20)31103-X

8. Belhadjer Z, Méot M, Bajolle F, Khraiche D, Legendre A, Abakka S, Auriau J, Grimaud M, Oualha M, Beghetti M, Wacker J, Ovaert C, Hascoet S, Selegny M, Malekzadeh-Milani S, Maltret A, Bosser G, Giroux N, Bonnemains L, Bordet J, di Filippo S, Mauran P, Falcon-Eicher S, Thambo JB, Lefort B, Moceri P, Houyel L, Renolleau S, Bonnet D (2020) Acute heart failure in multisystem inflammatory syndrome in children in the context of global SARSCoV-2 pandemic. Circulation 142:429-436. https://doi.org/10. 1161/CIRCULATIONAHA.120.048360 
9. Alsaied T, Tremoulet AH, Burns JC, Saidi A, Dionne A, Lang SM, Newburger JW, de Ferranti S, Friedman KG (2021) Review of cardiac involvement in multisystem inflammatory syndrome in children. Circulation. 143:78-88. https://doi.org/10.1161/ CIRCULATIONAHA.120.049836

10. Blondiaux E, Parisot P, Redheuil A, Tzaroukian L, Levy Y, Sileo C, Schnuriger A, Lorrot M, Guedj R, Ducou le Pointe H (2020) Cardiac MRI in children with multisystem inflammatory syndrome associated with COVID-19. Radiology 297:E283-E288. https:// doi.org/10.1148/radiol.2020202288

11. Yang X, Chang Y, Wei W (2016) Endothelial dysfunction and inflammation: immunity in rheumatoid arthritis. Mediat Inflamm 2016:6813016-6813019. https://doi.org/10.1155/2016/6813016

12. Zhang J, Tecson KM, McCullough PA (2020) Endothelial dysfunction contributes to COVID-19-associated vascular inflammation and coagulopathy. Rev Cardiovasc Med 21(315):-319. https://doi. org/10.31083/j.rcm.2020.03.126

13. Rohlenova K, Veys K, Miranda-Santos I, De Bock K, Carmeliet P (2018 Mar) Endothelial cell metabolism in health and disease. Trends Cell Biol 28(3):224-236. https://doi.org/10.1016/j.tcb. 2017.10.010

14. Raitakari OT, Celermajer DS (2000 Nov) Flow-mediated dilatation. Br J Clin Pharmacol 50(5):397-404. https://doi.org/10.1046/j. 1365-2125.2000.00277.x

15. Safar ME (2018 Feb) Arterial stiffness as a risk factor for clinical hypertension. Nat Rev Cardiol 15(2):97-105. https://doi.org/10. 1038/nrcardio.2017.155

16. Green SJ (2020) Covid-19 accelerates endothelial dysfunction and nitric oxide deficiency. Microbes Infect 22:149-150. https://doi. org/10.1016/j.micinf.2020.05.006

17. Ciftel M, Turan O, Simșek A, Kardelen F, Akçurin G, Ertuğ H (2014) Assessment of atrial electromechanical delay in children with acute rheumatic fever. Cardiol Young 24:27-32. https://doi. org/10.1017/S104795111200193X

18. Çiftel M, Ertuğ H, Parlak M, Akçurin G, Kardelen F (2014) Investigation of endothelial dysfunction and arterial stiffness in children with type 1 diabetes mellitus and the association with diastolic dysfunction. Diab Vasc Dis Res 11:19-25. https://doi. org/10.1177/1479164113508564

19. Feldstein LR, Rose EB, Horwitz SM, Collins JP, Newhams MM, Son MBF, Newburger JW, Kleinman LC, Heidemann SM, Martin AA, Singh AR, Li S, Tarquinio KM, Jaggi P, Oster ME, Zackai SP, Gillen J, Ratner AJ, Walsh RF, Fitzgerald JC, Keenaghan MA, Alharash H, Doymaz S, Clouser KN, Giuliano JS Jr, Gupta A, Parker RM, Maddux AB, Havalad V, Ramsingh S, Bukulmez H, Bradford TT, Smith LS, Tenforde MW, Carroll CL, Riggs BJ, Gertz SJ, Daube A, Lansell A, Coronado Munoz A, Hobbs CV, Marohn KL, Halasa NB, Patel MM, Randolph AG (2020) Overcoming COVID-19 Investigators; CDC COVID-19
Response Team. Multisystem Inflammatory Syndrome in U.S. Children and Adolescents. N Engl J Med 383:334-346. https:// doi.org/10.1056/NEJMoa2021680

20. Centers for Disease Control and Prevention. Information for healthcare providers about multisystem inflammatory syndrome in children (MIS-C). May 29, 2020. https://www.cdc.gov/mis-c/ hcp/. Accessed June 13, 2020.

21. World Health Organization. Multisystem inflammatory syndrome in children and adolescents temporally related to COVID-19. Scientific Brief. May 13, 2020. https://www.who.int/publications/ i/item/multisystem-inflammatory-syndrome-in-children-andadolescents-with-covid-19 Accessed May 5, 2021.

22. Matsubara D, Kauffman HL, Wang Y, Calderon-Anyosa R, Nadaraj S, Elias MD, White TJ, Torowicz DL, Yubbu P, Giglia TM, Hogarty AN, Rossano JW, Quartermain MD, Banerjee A (2020) Echocardiographic findings in pediatric multisystem inflammatory syndrome associated with COVID-19 in the United States. J Am Coll Cardiol 76:1947-1961. https://doi.org/10.1016/j.jacc. 2020.08.056

23. Fox SE, Lameira FS, Rinker EB, Vander Heide RS (2020) Cardiac endotheliitis and multisystem inflammatory syndrome after COVID-19. Ann Intern Med 173:1025-1027. https://doi.org/10. 7326/L20-0882

24. Diorio C, McNerney KO, Lambert M, Paessler M, Anderson EM, Henrickson SE et al (2020) Evidence of thrombotic microangiopathy in children with SARS-CoV-2 across the spectrum of clinical presentations. Blood Adv 4:6051-6063. https://doi.org/10.1182/ bloodadvances. 2020003471

25. Zuchi C, Tritto I, Carluccio E, Mattei C, Cattadori G, Ambrosio G (2020) Role of endothelial dysfunction in heart failure. Heart Fail Rev 25:21-30. https://doi.org/10.1007/s10741-019-09881-3

26. Leask RL, Jain N, Butany J (2003) Endothelium and valvular diseases of the heart. Microsc Res Tech 60:129-137. https://doi.org/ 10.1002/jemt.10251

27. Perico L, Benigni A, Casiraghi F, Ng LFP, Renia L, Remuzzi G (2021) Immunity, endothelial injury and complement-induced coagulopathy in COVID-19. Nat Rev Nephrol 17:46-64. https://doi. org/10.1038/s41581-020-00357-4

28. Huertas A, Montani D, Savale L, Pichon J, Tu L, Parent F, Guignabert C, Humbert M (2020) Endothelial cell dysfunction: a major player in SARS-CoV-2 infection (COVID-19)? Eur Respir J 56(1):2001634. https://doi.org/10.1183/13993003.01634-2020

29. Su JB (2015) Vascular endothelial dysfunction and pharmacological treatment. World J Cardiol 7:719-741. https://doi.org/10.4330/ wjc.v7.i11.719

Publisher's note Springer Nature remains neutral with regard to jurisdictional claims in published maps and institutional affiliations. 